\title{
Bleeding Index and Monocyte Chemoattractant Protein 1 as Gingival Inflammation Parameters after Chemical-Mechanical Retraction Procedure
}

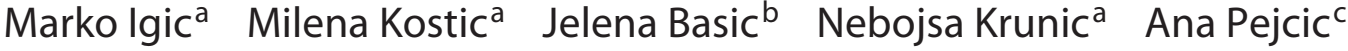 \\ Nikola Gligorijevic ${ }^{a} \quad$ Aleksandra Milic Lemic $^{d}$ \\ ${ }^{a}$ Department of Prosthodontics, Medical Faculty, University of Niš, Niš, Serbia; ${ }^{b}$ Department of Biochemistry, \\ Medical Faculty, University of Niš, Niš, Serbia; ' Department of Oral Medicine and Periodontology, Medical Faculty, \\ University of Niš, Niš, Serbia; ${ }^{d}$ Department of Prosthodontics, Dental School, University of Belgrade, Belgrade, Serbia
}

\section{Significance of the Study}

- Two different retraction agents were compared with regard to the gingival bleeding index and levels of monocyte chemoattractant protein 1 (MCP-1).

- A statistically significant increase was observed in the gingival bleeding index $24 \mathrm{~h}$ after the application of the gingival retraction agent.

- A statistically significant increase in MCP-1 values was observed over the entire study period.

\section{Keywords}

Gingival bleeding index · Retraction - Inflammation - MCP-1 . Monocyte chemoattractant protein - Astringent

\begin{abstract}
Objective: A widely used chemical-mechanical method of gingival retraction can cause gingival tissue damage. The aim of this study was to test the influence of the chemicalmechanical gingival retraction procedures on the gingival bleeding index $(\mathrm{GBI})$ and the salivary concentration of monocyte chemoattractant protein 1 (MCP-1) as an indicator of inflammatory changes in the gingiva. Materials and Methods: The effects of 2 different retraction agents (aluminum chloride and ferric sulfate) were compared, particularly their tissue damaging effect during tooth preparation. Therefore, $\mathrm{GBI}$ values and the salivary concentration of MCP-1 were assessed during the chemical-mechanical
\end{abstract}

$\begin{array}{ll}\text { karger@karger.com } & \text { ( ) 2020 The Author(s) Karger } \\ \text { www.karger.com/mpp } & \text { Published by S. Karger AG, Basel Open access } \\ \text { Karger } & \begin{array}{l}\text { This is an Open Access article licensed under the Creative Commons } \\ \text { Attribution-NonCommercial-4.0 International License (CC BY-NC) } \\ \text { (http://www.karger.com/Services/OpenAccessLicense), applicable to } \\ \text { the online version of the article only. Usage and distribution for com- } \\ \text { mercial purposes requires written permission. }\end{array}\end{array}$

method of gingival retraction in a homogenous group of respondents. The subjects $(n=60)$ were divided into 2 experimental groups ( $\mathrm{G} 1$ and $\mathrm{G} 2$ ) regarding the need for tooth preparing and making artificial crowns. Each group was further divided into 2 subgroups (R1 and R2) according to the type of the gingival retraction agent used (aluminum chloride and ferric sulfate). Results: Compared to the values at the study start, a statistically significant increase in GBI and salivary MCP-1 ( $p<0.001) 1$ day after gingival retraction agent application was observed in both experimental groups. After $72 \mathrm{~h}$, the values were lower than in the second observation period but still statistically significantly higher compared to the study start ( $p<0.001$ ), which indicated the reversibility of the tissue changes. Conclusion: Higher values of the investigated parameters were observed in the group of subjects with prepared teeth, and clinical changes were more pronounced after the use of ferric sulfate.

(C) 2020 The Author(s)

Published by S. Karger AG, Basel

Marko Igic

Department for Prosthodontics, Medical Faculty

University of Niš

RS-18000 Niš (Serbia)

saigic@yahoo.com 


\section{Introduction}

Fixed prosthodontic appliance therapy involves making artificial crowns or bridges for the purpose of rehabilitating the dental arch. A well-made fixed restoration intimately rests on the dental tissue in the region of the preparation boundary (demarcation line). Gingival retraction is necessary in cases in which the demarcation line is localized at or below the edge of the gingiva, with the aim of providing accurate imprinting [1].

The most commonly used chemical-mechanical method of gingival retraction involves the use of a retraction cord soaked in astringent fluid, most commonly aluminum and iron salts, to allow the marginal gingiva to reversibly dislocate apically and laterally and to permit the region of the gingival sulcus to drain. The mechanism of action of astringent is protein precipitation and inhibition of transcapillary movement of plasma proteins [2]. Astringent retraction agents reduce cellular permeability and drain gingival tissue, leading to its reversible recession. Protein precipitation and denaturation can cause local tissue damage [2-5]. The potential toxicity of aluminum chloride at concentrations $>10 \%$ has been demonstrated $[6,7]$. Ferric sulfate coagulates blood, but often hemorrhage recurs after removal of the retraction cord, and the opening of the gingival sulcus is less than what is seen when aluminum salts are used [8]; the authors have reported possible tissue damage caused by ferric sulfate $[8,9]$.

The first signs of damage caused by the chemicalmechanical retraction procedure appear on the gingival tissue, and the resulting inflammation leads to an increase in the concentration of proinflammatory cytokines and immunoglobulins in saliva, as well as to structural changes in the tissue itself [10]. Gingival indices allow the numerical expression of the resulting changes and objective evaluation of the periodontal condition. Proinflammatory cytokines are associated with oral tissue destruction, proteinase induction, and bone decomposition, and their increased production has been observed in numerous oral diseases $[11,12]$. Monocyte chemoattractant protein 1 (MCP-1) is a proinflammatory chemotactic cytokine that can trigger different groups of leukocytes through interaction with specific receptors and can induce the formation of specific inflammatory infiltrates; thus, it can be considered a sign of newly developed inflammation $[13,14]$. Early detection of inflammation markers after standard dental procedures may help to prevent the occurrence of more severe periodontal damage.

Gingival Inflammation Parameters after the Retraction Procedure
Table 1. Patient distribution in the experimental study groups and subgroups

\begin{tabular}{lll}
\hline Subgroup & $\begin{array}{l}\text { G1 patients } \\
\text { with 1 } \\
\text { prepared } \\
\text { tooth }\end{array}$ & $\begin{array}{l}\text { G2 patients } \\
\text { without } \\
\text { prepared } \\
\text { tooth }\end{array}$ \\
\hline $\begin{array}{l}\text { Experimental group } \\
\text { R1: } 25 \% \mathrm{AlCl}_{3} \text { (aluminium chloride) } \\
\begin{array}{l}\text { Racestyptin }(\text { Septodont, USA) } \\
\text { R2: } 15.5 \% \mathrm{Fe}_{2}\left(\mathrm{SO}_{4}\right)_{3} \text { (ferric sulfate) } \\
\text { Astringedent, Ultradent, SAD }\end{array}\end{array}$ & 15 & 15 \\
\hline Total, $n$ & 15 & 15 \\
\hline
\end{tabular}

The aim of this study was to test the influence of the chemical-mechanical gingival retraction procedure on gingival bleeding index values and the salivary MCP-1 concentration as an indicator of inflammatory changes in the gingiva.

\section{Materials and Methods}

\section{Subjects}

The study included 60 subjects of both sexes, nonsmokers, aged 20-40 years, with no systemic diseases and with a completely rehabilitated oral cavity. All subjects were examined and rehabilitated by the periodontist before the intervention, so that there were no inflammatory changes on the supporting dental tissues before examination onset. The subjects were divided into 2 experimental groups (G1 and G2) based on the need for tooth preparation and making artificial crowns. Each group was further divided into 2 subgroups (R1 and R2) [15] according to the type of the gingival retraction agent used (Table 1). Sample size was calculated using the commercial statistical program $\mathrm{G}^{*}$ Power for two-way null hypothesis testing and the $F$ test and ANOVA, respectively. The following parameters were specified: probability of type 1 error $\alpha=0.05$ and strength of the study of 0.8 . With such initial parameters and based on the publication by DI Venere et al. [16], a minimum sample size of at least 8 subjects per subgroup of both study groups was obtained.

\section{Methods}

Determining the time and extent of bleeding, GBI numerically indicated the activity of the inflammatory process in the gingiva. Testing was performed by probing the gingival sulcus with a bluntended periodontal probe. The intensity of resulting bleeding was scored based on the behavior of the gingiva after probing: 0 , no bleeding; 1, bleeding 10-30 s after probing; 2, bleeding during gingival probing; and 3, spontaneous bleeding of the gingiva. The examined index was determined by the same periodontologist before the retraction procedure as well as in other predicted retraction periods.

MCP-1 concentrations were determined using the human CCL2/MCP-1 Quantikine ELISA kit (sensitivity $10 \mathrm{pg} / \mathrm{mL}$ ). Saliva samples were centrifuged at $10,000 \mathrm{rpm}$ for $5 \mathrm{~min}$. The separated supernatant was frozen at $-80^{\circ} \mathrm{C}$ until analysis.

Med Princ Pract 2020;29:492-498 
Table 2. GBI values regarding the gingival retraction agent type during different observation periods

\begin{tabular}{lllll}
\hline Group & Subgroup & T0 & T1 & T2 \\
\hline G1 & R1 & $0.13 \pm 0.23(0.00)$ & $1.80 \pm 0.56^{* * *}(2.00)$ & $1.00 \pm 0.38^{* * *}(1.00)$ \\
& R2 & $0.60 \pm 0.60(1.00)$ & $2.33 \pm 0.24^{* * *}(2.50)$ & $1.57 \pm 0.62^{* * *}(1.50)$ \\
\hline G2 & R1 & $0.30 \pm 0.53(0.00)$ & $1.30 \pm 0.37^{* * *}(1.00)$ & $0.57 \pm 0.53^{* * *}(0.50)$ \\
& R2 & $0.33 \pm 0.59(0.00)$ & $1.63 \pm 0.61^{* * *}(2.00)$ & $0.77 \pm 0.59^{* * *}(0.50)$ \\
\hline
\end{tabular}

The values of the continuous variables given as means \pm SD. ${ }^{* * *} p<0.001$ vs. T0.

Table 3. The effect of gingival retraction agents on GBI values in groups G1 and G2 during the study period

\begin{tabular}{|c|c|c|c|c|c|}
\hline & \multicolumn{3}{|c|}{ Within-participant effects } & \multirow{2}{*}{$\begin{array}{l}\text { Between-participant } \\
\text { effects }\end{array}$} & \multirow{2}{*}{$\begin{array}{l}\text { Interaction } \\
\text { group } \times \text { time }\end{array}$} \\
\hline & $\mathrm{R} 1+\mathrm{R} 2$ & $\mathrm{R} 1$ & $\mathrm{R} 2$ & & \\
\hline \multicolumn{6}{|l|}{$G B I$} \\
\hline \multicolumn{6}{|l|}{ G1 } \\
\hline$p$ value & $<0.001^{* * *}$ & $<0.001^{* * *}$ & $<0.001^{* * *}$ & 0.8374 & 0.8374 \\
\hline Effect size & 0.8637 & 0.8933 & 0.8383 & 0.0056 & 0.0056 \\
\hline \multicolumn{6}{|l|}{ G2 } \\
\hline p value & $<0.001^{* * *}$ & $<0.001^{* * *}$ & $<0.001^{* * *}$ & 0.2871 & 0.1999 \\
\hline Effect size & 0.7870 & 0.8322 & 07657 & 0.0404 & 0.0566 \\
\hline
\end{tabular}

\section{Clinical Procedure}

Subjects in the G1 group had been indicated for making an artificial crown, i.e., the preparation of 1 tooth, which precedes the retraction procedure. The preparation demarcation was located $0.25-0.5 \mathrm{~mm}$ below the gingival level, with maximum preservation of the gingival tissue integrity. Tooth preparation was performed atraumatically by the same type of dental bur and by 3 trained therapists, thus reducing the possibility of gingival inflammation due to mechanical damage to the gingiva. Since there was no tooth preparation in group $\mathrm{G} 2$, the chemical retraction method was demonstrated on the upper left central incisor.

The chemical-mechanical method of gingival retraction involved the application of a retraction cord (Elite Cord, Zhermack SpA, Italy) of the appropriate diameter, impregnated with R1 or $\mathrm{R} 2$, into the gingival sulcus of the reference tooth for $5 \mathrm{~min}$. The retraction cord was atraumatically pressed by the same therapist along the entire scope of the tooth using a plastic instrument. The entire study period involved 3 observation periods: prior to (T0), and $24 \mathrm{~h} \mathrm{(T1)} \mathrm{and} 72 \mathrm{~h} \mathrm{(T2)} \mathrm{after} \mathrm{the} \mathrm{chemical-mechanical} \mathrm{retrac-}$ tion procedure. The first observation period (T0) in G1 was related to the time before tooth preparation. In each observation period, GBI was determined for the reference tooth, and a sample of nonstimulated saliva was collected into a sterile tube. Given that the test parameters in all subjects were determined prior to and after the retraction procedure, all samples collected before the treatment were considered as controls. Clinical procedures for making artificial crowns on prepared teeth followed the study period.

\section{Statistical Analysis}

The data were processed using the software for statistical data processing SPSS 15.0. The Mann-Whitney U test was used to assess significant differences $(p)$ of continuous variables between 2 independent subject groups. A value of $p<0.05$ was considered statistically significant. Changes in the arithmetic mean of the variables measured in the 3 observation periods in the study groups were analyzed using ANOVA for repeated measures (RM ANOVA). The effects of changes were defined by the values of the partial eta squared $\left(\eta \mathrm{p}^{2}\right)$ with the effect defined as "small" for parameter values $>0.01$, "medium," for values $>0.06$, and "large" for values $>0.14$.

\section{Results}

Table 2 shows a statistically significant increase in GBI values $(p<0.001) 24 \mathrm{~h}$ after the application of the gingival retraction agent in both experimental groups compared to the values at the beginning of the study. After $72 \mathrm{~h}$, the values were lower compared to the second observation period, but they were still statistically significantly higher compared to those at the study onset $(p<0.001)$.

The influence of the type of the gingival retraction agent on GBI in the experimental groups during the entire study period is shown in Table 3. Within both groups, G1 and G2, 
Table 4. Salivary concentration of MCP-1 (pg/mL) depending on the type of the gingival retraction agent during different observation periods

\begin{tabular}{lllll}
\hline Group & Subgroup & T0 & T1 & T2 \\
\hline G1 & R1 & $97.24 \pm 9.32(95.74)$ & $105.81 \pm 12.71^{* * *}(101.21)$ & $100.58 \pm 10.13^{* * *}(97.33)$ \\
& R2 & $93.52 \pm 6.37(94.21)$ & $105.68 \pm 8.24^{* * *}(103.51)$ & $97.62 \pm 5.66^{* * *}(96.83)$ \\
\hline G2 & R1 & $62.22 \pm 1.48(62.50)$ & $77.14 \pm 2.05^{* * *}(76.55)$ & $67.31 \pm 4.78^{* * *}(66.84)$ \\
& R2 & $66.25 \pm 3.85(67.78)$ & $69.48 \pm 4.89^{* * *}(70.25)$ & $67.76 \pm 4.16^{* * *}(68.29)$ \\
\hline
\end{tabular}

The values of the continuous variables are given as means \pm SD. ${ }^{* * *} p<0.001$ vs. T0.

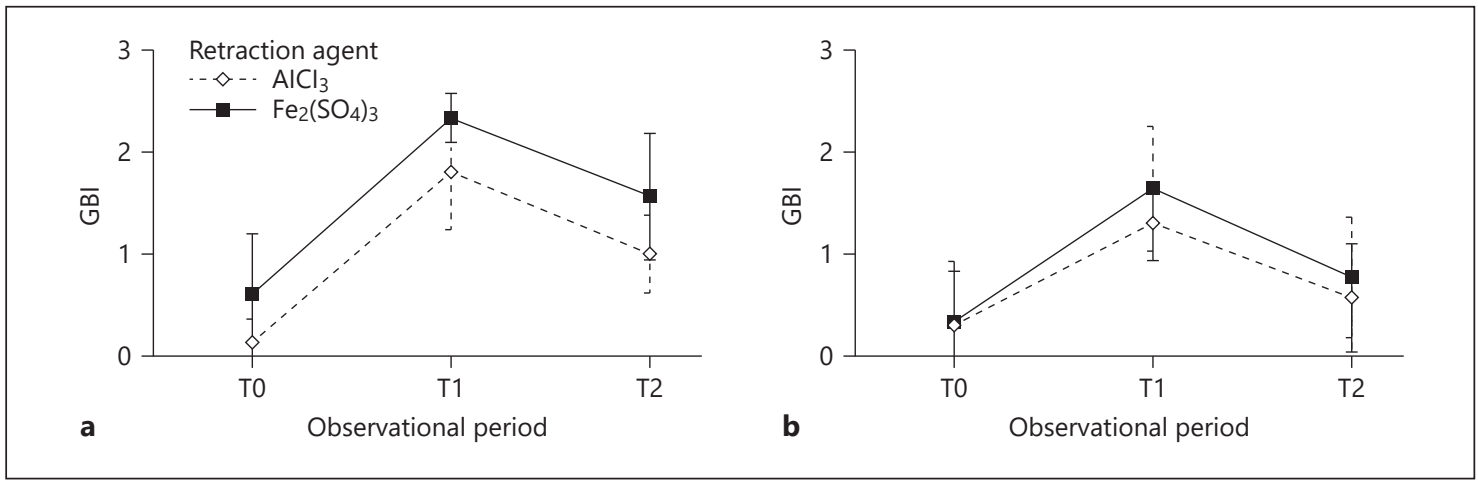

Fig. 1. GBI values during the study period in groups G1 (a) and G2 (b) with regard to the gingival retraction agent used.

a statistically significant increase in GBI values was found for both tested retraction agents and for all subjects during the entire study period $(p<0.001)$. The gingival retraction agents showed major effects on the GBI value. In both groups, the effect size was greater with the use of the aluminum chloride-based gingival retraction agent (R1). Testing the effects between subgroups (between participant effects) showed that they did not differ statistically significantly in GBI values over the entire follow-up period.

Changes in GBI values during the study period were similar in both groups of subjects (Fig. 1). One day after the retraction procedure, both experimental groups experienced a statistically significant increase in the salivary concentration of MCP-1 $(p<0.001)$. After $72 \mathrm{~h}$, the salivary concentration of MCP-1 was decreased compared to the second observation period, yet it remained statistically significantly higher than prior to the application of the gingival retraction agent $(p<0.001)$ (Table 4$)$.

The effect of the gingival retraction agent type on the salivary concentration of MCP-1 during the study period in groups G1 and G2 is shown in Table 5. Within these groups, a statistically significant increase in MCP-1 val-

Gingival Inflammation Parameters after the Retraction Procedure ues was observed over the entire study period $(p<0.001)$ for both retraction agent types and for all subjects, with a great effect of the retraction agent. Testing the effect of the retraction agent types between subgroups showed that they did not differ statistically significantly in MCP-1 concentrations throughout the study period, with a negligible effect of the gingival retraction agent used.

Changes in MCP-1 concentrations during the study period occurred in a statistically significantly different manner depending on the retraction agent type only in the group of subjects with nonprepared teeth $(p<0.001)$, with a great effect of the retraction agent. In group $G 1$, changes in MCP-1 concentrations did not occur in a statistically significantly different manner in the subgroups (Fig. 2).

\section{Discussion}

The study started from the assumption that the widely used chemical-mechanical procedure of gingival retraction during the production of fixed prosthetic compensations may damage the treated gingival tissue and may 


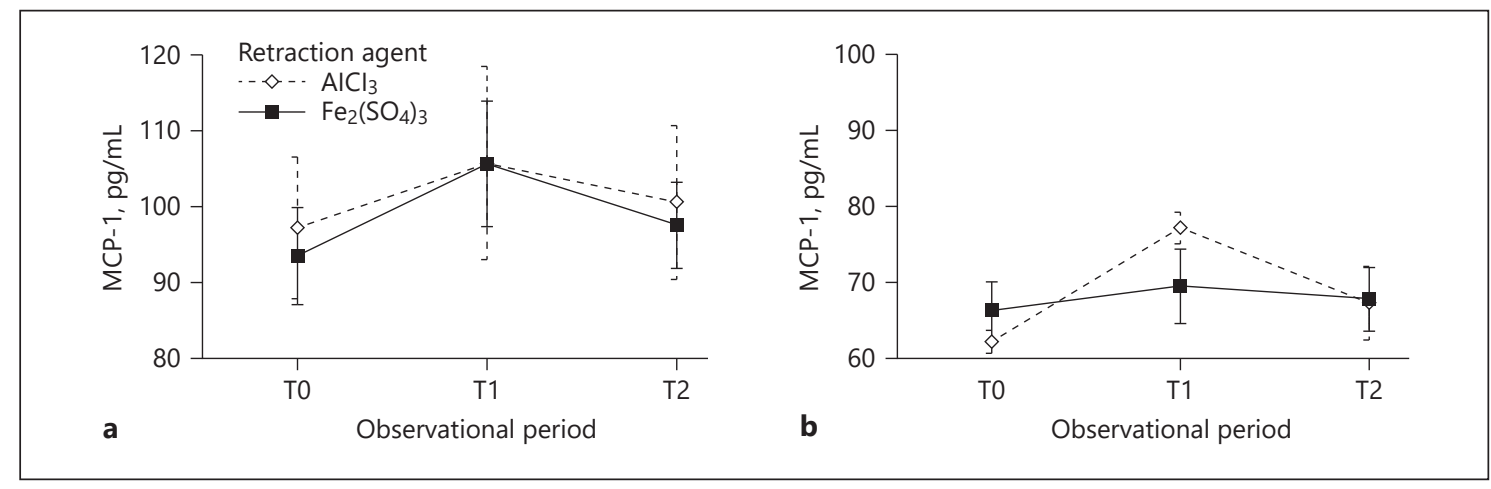

Fig. 2. MCP-1 concentrations (pg/mL) during the study period in groups G1 (a) and G2 (b) with regard to the gingival retraction agent used.

Table 5. The effect of gingival retraction agents on the salivary concentration of MCP-1 (pg/mL) in groups G1 and $\mathrm{G} 2$ during the study period

\begin{tabular}{|c|c|c|c|c|c|}
\hline & \multicolumn{3}{|c|}{ Within-participant effects } & \multirow{2}{*}{$\begin{array}{l}\text { Between-participant } \\
\text { effects }\end{array}$} & \multirow{2}{*}{$\begin{array}{l}\text { Interaction } \\
\text { group } \times \text { time }\end{array}$} \\
\hline & $\mathrm{R} 1+\mathrm{R} 2$ & $\mathrm{R} 1$ & $\mathrm{R} 2$ & & \\
\hline \multicolumn{6}{|l|}{$M C P-1$} \\
\hline \multicolumn{6}{|l|}{ G1 } \\
\hline p value & $<0.001^{* * *}$ & $<0.001^{* * *}$ & $<0.001^{* * *}$ & 0.4750 & 0.1313 \\
\hline Effect size & 0.7140 & 0.6782 & 0.7425 & 0.0184 & 0.0740 \\
\hline \multicolumn{6}{|l|}{ G2 } \\
\hline p value & $<0.001^{* * *}$ & $<0.001^{* * *}$ & $<0.001^{* * *}$ & 0.3820 & $<0.001^{* * *}$ \\
\hline Effect size & 0.8089 & 0.8713 & 0.6393 & 0.0274 & 0.6427 \\
\hline
\end{tabular}

cause an acute inflammatory reaction, as evidenced by the increase in the GBI value, which serves as a clinical parameter, as well as the salivary concentration of MCP-1, a marker of inflammation.

The results of the study indicate reversible damage to the gingival tissue after the application of both retraction agents studied. The clinical observation of the gingival tissue in the subjects revealed a mild-to-moderate inflammation 1 day after the retraction procedure, which resulted in bleeding during gingival sulcus probing in all subjects in the prepared teeth group as well as after the application of ferric sulfate in subjects with nonprepared teeth. Three days after the gingival retraction, inflammation was reduced, and bleeding after probing was mild in group G1, while in group G2 it was less. These results are in agreement with the results of other authors, who demonstrated the recovery of oral tissue after retraction procedures [17, 18]. Higher GBI values in subjects with prepared teeth indicated a certain mechanical tissue injury that contributed to the inflammatory response of the gingiva [19].

Proinflammatory cytokines play important roles in triggering and maintaining inflammatory and immune responses [10]. The chemical-mechanical retraction method led to an increase in the MCP-1 concentration in the subjects of both experimental groups, which is in a positive correlation with the results of the clinical parameter monitored. A decrease in MCP-1 with time proved the reversibility of the resulting changes. The type of the retraction agent used did not affect the measured MCP-1 concentration, but its mean values were higher in group G1, which emphasizes the importance of tooth preparation in the inflammatory reaction observed in the gingival tissue.

Our results are consistent with the results of other studies published to date and indicate that increased MCP-1 secretion is an indicator of periodontal damage [20-22]. Garlet et al. [21] demonstrated that MCP-1 in diseased gin- 
gival tissue supports the maturation of monocytes into macrophages, whose role is to destroy pathogens and secrete proinflammatory mediators. Macrophage-released products such as IL- 1 and TNFa, in addition to contributing to the inflammatory reaction, also trigger bone decomposition [22]. Therefore, the chemotactic action MCP-1 on monocytes and macrophages can support chronic inflammatory responses and bone loss present in periodontopathy [12]. In the gingival fluid of patients with aggressive and chronic periodontitis, MCP-1 levels were higher than in healthy subjects $[23,24]$. In a study by Pradeep et al. [12], a proportionate decrease in MCP-1 levels was noted in the gingival fluid after periodontal therapy.

To date, the results of the potential iatrogenic effect of the chemical-mechanical retraction procedure have been obtained in in vitro and in vivo studies in experimental models, whereas studies in clinical conditions are insufficient and, at the same time, necessary from the professional point of view. The study of clinical parameters of gingival damage and the determination of the salivary concentration of the reference proinflammatory cytokine in a homogeneous group of patients have given an exact answer regarding potential side effects of the widely used chemical-mechanical method of gingival retraction. The right choice of clinical procedures and therapeutic agents diminishes iatrogenic damage that would compromise the effect of prosthetic therapy and reduce the durability of fixed restoration.

\section{Conclusion}

The bleeding index values and the salivary concentration of MCP-1 increased statistically significantly after the chemical-mechanical gingival retraction proce- dure, with a tendency to decrease over time, which indicated the reversibility of the resulting changes. Higher values of the studied parameters were observed in the group of subjects with prepared teeth, and clinical changes were more pronounced after the use of ferric sulfate, although no statistically significant difference was found.

\section{Acknowledgments}

This work was supported by the Faculty of Medicine, University of Niš, Serbia (No. 1114629-4/11).

\section{Statement of Ethics}

The study was conducted in accordance with the provisions of the Declaration of Helsinki and was approved by the Ethics Committee of the Faculty of Medicine, University of Niš, Serbia $(12-1250 / 9)$.

\section{Disclosure Statement}

The authors have no conflicts of interest to declare.

\section{Author Contributions}

Marko Igic, Milena Kostic, Nebojsa Krunic, Nikola Gligorijevic, and Aleksandra Milic Lemic made tooth preparations, performed the gingival retraction procedure, collected saliva samples and wrote part of the manuscript. Jelena Basic performed biochemical analysis and participated in the discussion of the results. Ana Pejcic determined GBI values and participated in the discussion of the results.

\section{References}

1 Tabassum S, Adnan S, Khan FR. Gingival retraction methods: A systematic review. J Prosthodont. 2017 Dec;26(8):637-43.

2 Fazekas A, Csempesz F, Csabai Z, Vág J. Effects of pre-soaked retraction cords on the microcirculation of the human gingival margin. Oper Dent. 2002 Jul-Aug;27(4):343-8.

3 Kostić I, Mihailović D, Najman S, Stojanović $\mathrm{S}$, Kostić M. The rabbit gingival tissue response to retraction liquids and tetrahydrozoline. Vojnosanit Pregl. 2014 Jan;71(1):46-51.

4 Nowakowska D, Saczko J, Kulbacka J, Choromanska A, Raszewski Z. Cytotoxic potential of vasoconstrictor experimental gingival re- traction agents: in vitro study on primary human gingival fibroblasts. Folia Biol (Praha). 2012;58(1):37-43.

5 Lodetti G, D’Abrosca F, Fontana P, Pavoni E, Gigola P. [Set up of in vitro methods able to detect the safety of astringent liquids]. Minerva Stomatol. 2004 Jun;53(6):361-7. Italian.

6 Kopač I, Sterle M, Marion L. Electron microscopic analysis of the effects of chemical retraction agents on cultured rat keratinocytes. J Prosthet Dent. 2002 Jan;87(1):51-6.

7 Tarighi P, Khoroushi M. A review on common chemical hemostatic agents in restor- ative dentistry. Dent Res J (Isfahan). 2014 Jul; 11(4):423-8.

8 Kostic I, Najman S, Kostic M, Stojanovic S. Comparative review of gingival retraction agents. Acta Med Median. 2012;51(1):81-4.

9 Akca EA, Yildirim E, Dalkiz M, Yavuzyilmaz $\mathrm{H}$, Beydemir B. Effects of different retraction medicaments on gingival tissue. Quintessence Int. 2006 Jan;37(1):53-9.

10 Keles ZP, Keles GC, Avci B, Cetinkaya BO, Emingil G. Analysis of YKL-40 acute-phase protein and interleukin-6 levels in periodontal disease. J Periodontol. 2014 Sep;85(9): 1240-6.
Gingival Inflammation Parameters after the Retraction Procedure
Med Princ Pract 2020;29:492-498

DOI: $10.1159 / 000506878$ 
11 Kostic M, Igic M, Jevtovic Stoimenov T, Pejcic A, Pesic Stankovic J. Determination of Salivary Myeloperoxidase, Immunoglobulin E, and Tumor Necrosis Factor- $\alpha$ after Complete Denture Insertion. Med Princ Pract. 2019; 28(4):347-51.

12 Pradeep AR, Daisy H, Hadge P. Gingival crevicular fluid levels of monocyte chemoattractant protein-1 in periodontal health and disease. Arch Oral Biol. 2009 May;54(5):503-9.

13 Luther SA, Cyster JG. Chemokines as regulators of T cell differentiation. Nat Immunol. 2001 Feb;2(2):102-7.

14 Gerard C, Rollins BJ. Chemokines and disease. Nat Immunol. $2001 \mathrm{Feb} ; 2(2): 108-15$.

15 Maischberger C, Stawarczyk B, von Hajmasy A, Liebermann A. Hemostatic gingival retraction agents and their impact on prosthodontic treatment steps: A narrative review. Quintessence Int. 2018;49(9):719-32.
16 DI Venere D, Pettini F, Nardi GM, Laforgia A, Stefanachi G, Notaro V, et al. Correlation between parodontal indexes and orthodontic retainers: prospective study in a group of 16 patients. Oral Implantol (Rome). 2017 Apr; 10(1):78-86.

17 Phatale S, Marawar PP, Byakod G, Lagdive SB, Kalburge JV. Effect of retraction materials on gingival health: A histopathological study. J Indian Soc Periodontol. 2010 Jan;14(1): 35-9.

18 Chandra S, Singh A, Gupta KK, Chandra C, Arora V. Effect of gingival displacement cord and cordless systems on the closure, displacement, and inflammation of the gingival crevice. J Prosthet Dent. 2016 Feb;115(2):177-82.

19 Felpel LP. A review of pharmacotherapeutics for prosthetic dentistry: part I. J Prosthet Dent. 1997 Mar;77(3):285-92.

20 Tonetti MS, Imboden MA, Gerber L, Lang NP, Laissue J, Mueller C. Localized expression of mRNA for phagocyte-specific chemotactic cytokines in human periodontal infections. Infect Immun. 1994 Sep;62(9):4005-14.
21 Garlet GP, Martins W Jr, Ferreira BR, Milanezi CM, Silva JS. Patterns of chemokines and chemokine receptors expression in different forms of human periodontal disease. J Periodontal Res. 2003 Apr;38(2):210-7.

22 Baker PJ. The role of immune responses in bone loss during periodontal disease. Microbes Infect. 2000 Aug;2(10):1181-92.

23 Emingil G, Atilla G, Hüseyinov A. Gingival crevicular fluid monocyte chemoattractant protein-1 and RANTES levels in patients with generalized aggressive periodontitis. J Clin Periodontol. 2004 Oct;31(10):829-34.

24 Kurtiş B, Tüter G, Serdar M, Akdemir P, Uygur C, Firatli E, et al. Gingival crevicular fluid levels of monocyte chemoattractant protein- 1 and tumor necrosis factor-alpha in patients with chronic and aggressive periodontitis. J Periodontol. 2005 Nov;76(11):184955. 